\title{
Critical predictors of burnout among civil engineers at construction sites: a structural equation modelling
}

\author{
Gulden Gumusburun Ayalp \\ Department of Architecture, Hasan Kalyoncu Universitesi, Gaziantep, Turkey
}

Received 18 December 2020

Revised 4 March 2021

24 April 2021

Accepted 19 July 2021

\begin{abstract}
Purpose - The construction industry has always been regarded as a stressful and task-driven industry with high levels of work pressure. When the stressful situations are prolonged, job burnout becomes unavoidable for construction professionals. The purpose of the present paper is to investigate the critical predictors of burnout among civil engineers at construction sites in Turkey and identify the impact of those determined burnout predictors on various burnout dimensions.

Design/methodology/approach - The possible causes of burnout for civil engineers at construction sites were determined using an extensive literature review and were further studied using a questionnaire. The obtained data were analysed statistically using SPSS 22 and LISREL 8.7 software. Correlation analysis, exploratory and confirmatory analysis, and structural equation modelling were performed on this collected data, and a structural model was developed.

Findings - Three critical factors affecting burnout levels of civil engineers in construction sites were determined; among them "organisational injustice" and "competitive pricing and lack of contract management" were identified as the critical predictors of burnout in the emotional-exhaustion and cynicism dimensions. Based on these predictors, potential solutions and recommendations are proposed that are anticipated to decrease the burnout among civil engineers at construction sites.

Originality/value - Although there are several works of research regarding the burnout among construction professionals, there is limited research that has provided insight into the specific factors causing burnout among civil engineers. This research presents a structural model of the predictors obtained by a confirmatory factor analysis for decreasing the burnout level of civil engineers at construction sites. The current study represents the first comprehensive quantitative determination of the factors and predictors of burnout among civil engineers at construction sites in Turkey.
\end{abstract}

Keywords Construction site, Civil engineers, Burnout, Structural equation modelling

Paper type Research paper

\section{Introduction}

The construction industry is labour-intensive, complex, high-risk, and discrete in nature. It has high working demands, heavy workloads, long construction periods, and thereby, increased stress. Completing a construction project requires the completion of several tasks within a limited time and the expected budget with high quality. Construction professionals are often required to work for long and irregular hours in fast-track construction projects. Hence, these factors can frequently result in stressful work environments for construction professionals (Yip and Rowlinson, 2009), and therefore, a majority of construction professionals experience stress (CIOB, 2006; Poon et al., 2013). Stress has a significant effect on employees and their organisations (Leung et al., 2011). A prolonged job stress may provoke job burnout that will not only influence the personal life of a construction professional, but will also lead to time and cost overruns, and declining customer satisfaction. The overall result of the burnout could be a negative effect on the project performance (Leung et al., 2011, 2012, 2012; Poon et al., 2013; Yang et al., 2017).

Burnout is a psychological phenomenon consisting of feelings, motives, attitudes, and expectations that affect individuals negatively causing associated problems like distress,

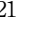


discomfort, and negative consequences (Schaufeli et al., 2017). While an individual experiences burnout, his/her job performance declines and absenteeism or actual turnover increases. Since civil engineers at construction sites serve all the stakeholders of a construction project, their burnout could not only directly influence the efficiency of the project team, but also have a significant effect on the performance of the project and even the organisation (Jugdev et al., 2018; Sun et al., 2020). Moreover, individuals experiencing burnout are known to argue with others and disrupt job tasks, exerting a negative impact on their colleagues.

Since construction projects tend to be large-scale, complex, and integrated (Luo et al., 2017), they require professionals to dedicate more energy and time at work. Furthermore, construction professionals are generally expected to endure immense pressure during the life cycle of the project to carry out optimal project performance. Therefore, this circumstance puts construction professionals at a high risk of experiencing job burnout (Leung et al., 2009).

There are several types of construction professionals; architects, civil engineers, construction managers, etc. who work on various jobs like contracting, designing, and supervising the construction site. The primary role of civil engineers is to design, manufacture, construct, operate, and maintain the particular products or services with which their organisations are concerned, with due consideration to safety, reliability, and environmental factors, as well as financial, economic, commercial, and statutory limitations (HKIE, 2007).

Civil engineers may work for consulting and contracting organisations. Engineers working in consulting firms are generally assigned an office and work on design, selection of materials, and monitoring of the work. Whereas, civil engineers working in contracting organisations are appointed at a construction site and are primarily responsible for the coordination, planning, arrangement of the workforce, machines and materials, supervision, control of progress, quality, and budget, as well as compliance with legal requirements in terms of safety and environmental issues (Yip and Rowlinson, 2009). Due to the multidimensional and dynamic nature of the work, civil engineers at construction sites are often demanded to accomplish the duties of the construction project managers, including balancing the expectations of several stakeholders. Therefore, the probability for a role conflict is high. Hence, civil engineers employed in contracting departments have more experience with stressful circumstances than those in government departments and the consulting industry ( $\mathrm{Ng}$ et al., 2005). Similar results were obtained by Lingard (2003).

In Turkey, construction professionals experience a high amount of stress in their work environment. Additionally, they have several stressors due to the characteristics of their job. As a consequence, the Turkish construction industry suffers from productivity issues (Kazaz et al., 2008), poor quality (Kazaz and Birgönül, 2005; Turk, 2006), and conflicts (Öcal et al., 2006) that influence the burnout of the civil engineers, and consequently, the project performance (Işık et al., 2010).

Therefore, researching the factors influencing burnout and determining the predictors of burnout among construction professionals is important. Although there are several works of research on the burnout among construction professionals all around the world, there is no specific study investigating this subject in the Turkish construction industry. The main purpose of this research is to identify the major predictors of burnout experienced by civil engineers at construction sites in Turkey. To achieve this aim, causes that induce burnout are defined from the literature. Exploratory and confirmatory factor analyses were then conducted to determine the main types of burnout factors. The index of relative importance was conducted to rank the severity of the identified challenges and identify the most critical burnout causes and factors. A correlation analysis was used to identify the relationships among the burnout factors. Finally, structural equation modelling (SEM) was applied to cross-check the inter-relationships among the burnout factors and establish an integrated 
model for burnout predictors. This represents an important aspect of differentiation from the former researches.

\section{Theoretical background}

\subsection{Burnout and sources of burnout among civil engineers at construction}

Based on the most widely cited definition, burnout is a psychological syndrome of emotional exhaustion, cynicism, and professional inefficacy experienced in response to chronic job stressors (Maslach, 1993). According to Maslach (1993), burnout can be measured by three dimensions: emotional exhaustion, cynicism, and professional inefficacy. Emotional exhaustion defines physical and mental fatigue and a lack of motivation. Emotional exhaustion is the primary quality of burnout and the most obvious manifestation of this complex syndrome. Cynicism is an attempt to put distance between oneself and service recipients by actively ignoring the qualities that make them unique and engaging people. Distancing is such an immediate reaction to exhaustion that a strong relationship from exhaustion to cynicism is found consistently in burnout research, across a wide range of organisational and occupational settings (Maslach et al., 2001). Professional inefficacy measures both the social and non-social aspects of occupational accomplishments (Leiter and Schaufeli, 1996). Individuals experiencing burnout demonstrate negative attitudes at their workplace and a reduction in job performance. Moreover, burnout is a phenomenon of stress that probably has significant negative health impacts on the individual and may affect the person's family life (Lingard et al., 2012). All these outcomes demonstrate high risks, not only for the individual and his/her personal life, but also, for the place where he/she works (Sun et al., 2020).

A previous study on burnout indicated that, work-related stressors originating from the job, organization, and social aspects have been shown to be major predictors of burnout (Leiter and Maslach, 2001). Therefore, causes related to job resources and/or job demands can potentially be predictors of burnout. A single cause is not sufficient for predicting burnout. Causes that are similar in nature combine and constitute a factor to serve as potential predictors. For instance, according to the results of a pioneering study in this field, causes such as fairness of efforts, responsibilities, and workload can be combined into organizational injustice, which is a critical burnout predictor for project managers (Yang et al., 2018).

As a specific result is required on the delivery of a construction project, there is no particular template to follow. Owing to the multidimensional nature of construction work, civil engineers at construction sites generally perform the role of construction managers that leads to role conflict, which might have severe life-threatening consequences. Within this context, role ambiguity and role conflict are commonly experienced by civil engineers at construction sites. These are significant of burnout and can be considered as predictors of burnout for construction professionals (Yip and Rowlinson, 2009). Sun et al. (2020) reported that role ambiguity is an important predictor for burnout among construction professionals and comprises role conflict, emotional demands, and work-home interference.

Providing and improving health and safety obligations and a fear of probable and unexpected occupational accidents that may result in death promote job-related stress amongst civil engineers at construction sites (Lingard, 2003). Another compelling cause of burnout is long and irregular work hours, which has been identified as a major predictor of burnout, especially in the emotional-exhaustion dimension (Leung et al., 2007; Yip and Rowlinson, 2009). Moreover, many civil engineers at construction sites encounter unrealistic demands and intense constraints to deliver projects on time and within the budget (Pinto et al., 2014). Critical
predictors of
burnout 
In view of the abovementioned reasons, civil engineers at construction sites are inclined to experience depression and anxiety, which are significant psychological problems. Due to the nature of the construction site, most civil engineers at construction sites are prone to pursue overachievement. While they encounter errors and failures during the construction process, they accuse themselves, thus causing the internalization of problems (Jugdev et al., 2018). These troubles collectively lead to negative symptoms such as chronic tiredness and low mood that are characterised as specific manifestations of burnout (Yang et al., 2017).

To ensure the benefit of organisational behaviour and occupational health, research works referring to burnout have broadened expeditiously across the world. Although workers in labour-intensive industries often experience burnout, the existing research is focused on waiters, nurses, teachers, etc. rather than construction professionals. There are limited empirical studies concerning the burnout among construction professionals (Jugdev et al., 2018; Yang et al., 2017, 2018; Wu et al., 2018; Sun et al., 2020; Zhang et al., 2020; Lee et al., 2020).

Two significant models named the conservation of resources model-COR (Hobfoll, 2001) and job demands-resources model-JD-R (Demerouti et al., 2001) are extensively used in burnout research works to help explain the phenomena. Both the models concentrate on the instability between job resources and job demands.

According to Demerouti et al. (2001), job demands are the social, physical, or organisational standpoints of the job that involves long-term physical and/or psychological effort; for example, physical demands and perceived workload (Moore, 2000; Bakker et al., 2005). Job resources are the social, organisational, and occupational resources that are helpful and useful for success in task objectives. External rewards and opportunities for growth and autonomy are examples of job resources (Demerouti et al., 2001; Gallstedt, 2003; Bakker and Demerouti, 2017). Job demands and job resources are negatively correlated (Yan et., 2018), and they are the predictors of burnout. Job demands are unique predictors of exhaustion, whereas job resources are important predictors of cynicism and inefficacy (Leiter, 1993).

The COR model assumes that people are always prone to conserve, recover, and acquire valuable resources to maintain the capacity to address demands as they arise (Hobfoll, 1989). Job demands and job resources are two independent paths to burnout according to the COR model.

The JD-R model is focused on the belief that burnout originates when people encounter job demands continuously and lack available resources. The JD-R model assumes that burnout is a combined result and effect of job resources and job demands, on the contrary to the COR model (Demerouti et al., 2001). This result was modified by several researchers. Schaufeli and Bakker (2004) stated that job resources and job demands are not independent but negatively related. Bakker and Demerouti (2017) stated that there is a relationship between job resources and job demands after analysing the development of the job demands-resources theory over 15 years. Additionally, several scholars have appealed to explore the joint effect of job demands and job resources on burnout.

Job demands and job resources constitute important aspects in the framework of burnout factors in all disciplines. Therefore, it is significant to identify the critical factors of burnout among civil engineers at construction sites in more detail. From this section onwards, this study is focused on the JD-R model to determine the critical predictors of burnout among civil engineers at construction sites. In this regard, a systematic review of the existing literature is required. To provide a comprehensive image of the causes that induce burnout, steps for literature selection were followed within the realistic review method as described by Pawson et al. (2005). As a result, forty-one causes related to job demand and job resources were identified and listed in Table 1. 
Code of causes

BC1

BC2

BC3

BC4

BC5

BC6

BC7

BC8

BC9

$\mathrm{BC} 10$

BC11

$\mathrm{BC} 12$

$\mathrm{BC} 13$

BC15

BC16

BC17

BC18

BC19

BC20

BC21

BC22

BC23

BC24

BC25

BC26

BC27

BC28

BC29

BC30

BC31
Causes of burnout

Reference

[18], [22], [24], [37]

[18], [22], [24], [37]

[18], [22], [24], [37]

[13], [15], [17]

[17], [22], [40]

[7], [13], [30], [40]

[18], [24], [37]

[22], [25], [28]

[4], [17], [22]

[4], [15], [17], [22]

[14], [22], [26], [29]

[4], [13]

[4], [6], [22]

[4], [21], [22], [41]

[4], [6], [22]

[4], [11], [22], [41]

[2], [20], [22], [38], [39], [41]

[2], [21], [38], [41]

[2], [21], [38]

[7], [21], [22], [23], [35], [36]

[6], [12], [21], [31], [35], [36]

[6], [12], [15], [31]

[6], [12], [31], [35], [36]

[6], [12], [31], [35], [36]

[4], [6], [22]

[4], [6], [8], [35], [36]

[7], [38], 35], [36]

[3], [5], [6], [32], [33]

[5], [9], [32]

[1], [3], [10], [13], [27], [35]

[6], [8], [11], [35], [36] except from salary rewards

Lack of promotion/promotion opportunity in the workplace managers or the unit chief Irregular and rush working hours Lack of participation in decision making Lack of career opportunities and vocational training
Critical predictors of burnout
Table 1. Causes of burnout 
ECAM

\begin{tabular}{|c|c|c|}
\hline $\begin{array}{l}\text { Code of } \\
\text { causes }\end{array}$ & Causes of burnout & Reference \\
\hline $\mathrm{BC} 32$ & $\begin{array}{l}\text { Lack of necessary and sufficient occupational safety } \\
\text { measures in the workplace }\end{array}$ & [1], [3], [21], [31] \\
\hline $\mathrm{BC} 33$ & Unclear job distribution, job definitions, role conflict & [4], [7], [10], [16], [29], [34], [35], [36], [39] \\
\hline $\mathrm{BC} 34$ & $\begin{array}{l}\text { Insufficient planning, control and supervision within } \\
\text { the organization }\end{array}$ & [4], [27] \\
\hline $\mathrm{BC} 35$ & $\begin{array}{l}\text { Lack of poor communication and coordination } \\
\text { between managers and employees }\end{array}$ & [3], [4], [19], [23], [33] \\
\hline $\mathrm{BC} 36$ & $\begin{array}{l}\text { Managers' negative attitudes and behaviours such as } \\
\text { dictatorship, bullying, intimidation and intimidation }\end{array}$ & [19], [23] \\
\hline $\mathrm{BC} 37$ & $\begin{array}{l}\text { Failure to apply or misapply the proposed designs by } \\
\text { manufacturers and subcontractors }\end{array}$ & [15], [25] \\
\hline$B C 38$ & $\begin{array}{l}\text { As a result of the short internship period in the civil } \\
\text { engineering education process and not being inspected } \\
\text { adequately, the appearance of engineers with little or no } \\
\text { implementation experience }\end{array}$ & {$[6],[25]$} \\
\hline BC39 & $\begin{array}{l}\text { The high number of colleagues who do the same job } \\
\text { almost without making money }\end{array}$ & [22], [25] \\
\hline $\mathrm{BC} 40$ & $\begin{array}{l}\text { The intervention and disrespect of the profession by } \\
\text { individuals outside the profession }\end{array}$ & [4], [22] \\
\hline $\mathrm{BC} 41$ & Lack of expertise at a specific engineering subject & {$[22],[25]$} \\
\hline \multicolumn{3}{|c|}{ 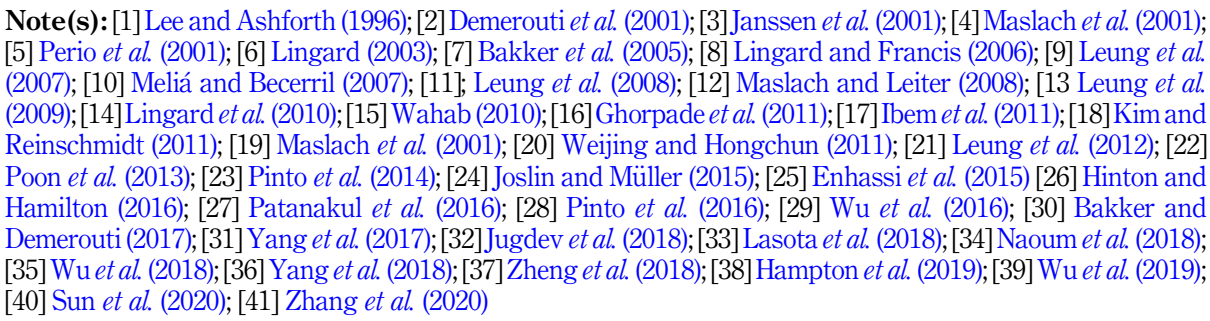 } \\
\hline
\end{tabular}

Table 1.

\subsection{Literature review}

Former researchers examined burnout on construction professionals quantitatively and mainly focussed on estimating whether the "clear effect" of each hypothesised independent variable is significantly associated with burnout (e.g. Yang et al., 2017; Pinto et al., 2014; Yang, 2018; Zhang et al., 2020). Lingard (2003) and Yip et al. (2005) adopted the Maslach Burnout Inventory-General Survey (MBI-GS) to measure the levels of job burnout among consulting and construction engineers. Another pioneering study in this field belongs to Leung et al. (2011), in which the researchers adopted SEM to investigate the impacts of job burnout, task-related stress, and physical stress on the job performance of construction project managers. However, Leung's research (2011) not only focuses on burnout, but also measures long-term psychological stress in conjunction with two stress indicators (e.g. work stress and physiological stress) to verify their impact on project manager performance. Lingard et al. $(2010,2012)$ conducted many studies on work-family relationship of construction professionals. Another significant research on the construction industry was conducted by Enshassi et al. (2015) in which the researchers determined the most vital job-related stressors that influence construction professionals' safety and job burnout in the Palestinian construction industry.

There has been a rapid climb in the number of research works related to burnout among construction professionals in the last 3 years. Yang et al. (2018) analysed the antecedent variables of job burnout among construction project managers from the perspective of 
organisational justice, considering several causes and dimensions, based on a job demandresource model. Researchers have proven that organizational injustice is a key predictor of burnout amount project managers. They proposed that material support from the organisation can reduce the level of employee burnout more effectively than spiritual support. Wu et al. (2018) developed a theoretical model introducing organisational support as a moderating variable for construction professionals. The researchers reported that work-family conflict is a strong burnout predictor and that organizational support is a mediator that can reduce burnout. Lasota et al. (2018) investigated representations of burnout syndrome among teachers, bank employees, building administration employees, and employees of renovation and construction companies. Researchers found that the burden of work conflicts with co-workers and superiors is the most stressful factor. Lee et al. (2020) examined how task demands and personal resources affect the productivity and safety performance of unskilled construction workers. As a result, greater task demands exacerbate burnout, especially emotional exhaustion. Thus, task demand is considered as a predictor of burnout among unskilled construction workers. Zhang et al. (2020) investigated the effects of two components of emotional behaviour, i.e. emotional display demands and emotional labour strategies, on the job burnout of construction project managers. Another major study was conducted by Sun et al. (2020) that investigated how different factors interact and work in combination to influence the burnout among construction professionals in China with a Fuzzy-set analysis.

Although research works exist regarding the burnout among construction professionals, the number of research works on the factors that induce burnout among civil engineers at construction sites is extremely limited. When this situation is evaluated on the basis of the Turkish construction industry, it is significant to note that there is no research on this subject. Moreover, in the previous studies, it can be clearly seen that the impacts or consequences of job burnout were examined. Therefore, research to determine the factors that induce burnout among civil engineers at construction sites, who play a significant but highly stressful role in completing projects successfully, is still lacking. In other words, there is a gap in the literature regarding the predictors of burnout among the civil engineers at construction sites.

Additionally, former research works on burnout in the construction industry have generalised the sample as construction professionals. However, there are several stakeholders in the construction process, who participate in design, construction, control, material supply, etc. The working conditions of the job distinctly vary depending on the characteristics of the related processes. Expecting a similar burnout level in civil engineers at offices and construction sites is unrealistic. Therefore, determining the factors that cause burnout by taking into consideration the conditions of the working place and the characteristics of the construction process is vital. The originality of the current research is in this aspect.

Unlike other limited studies on this subject, a wide spectrum questionnaire that focuses on burnout causes was prepared by surveying the literature and considering the JD-R burnout model. Then, the number of determined causes was reduced to identify the main burnoutinducing factors. Finally, a structural equation model was developed to present the critical burnout predictors with effect-size and relationships between burnout sub-dimensions. The most significant factor(s) that led to burnout could be determined as such.

\section{Research method and approach}

The current study employed a quantitative research design to identify and assess the critical factors affecting the burnout among civil engineers at construction sites. The research followed a multistage methodological framework consisting of determining the causes of the critical burnout factors, design of a questionnaire as a measurement instrument, data collection, and statistical analysis of the collected data. 
3.1 Determining the causes of burnout affecting civil engineers at construction sites

The first step of this research was the identification of the causes that affect the burnout levels of civil engineers at construction sites. Review of the literature was done by applying the realistic review method based on scientific realism (Pawson et al., 2005), which consists of five consecutive steps. The first step is identifying the review question. The particular review question was as follows: "what are the characteristics of the research included in the analysis and the effects found by them"? The effect indicator was the burden on civil engineers at construction sites as a subset of construction professionals, defined as job-related stressors (job-demand and job-resources).

The second stage is the initial theory and mechanism.JD-R model was adopted as the initial theory as explained in section 2.1.

Searching and selecting primary studies is the third stage. To identify the causal structure that best explains the phenomenon in the construction industry, the study set the strategy of exploring electronic databases from October to November 2019. The data were updated in March 2020. The search terms were as follows: (1) for population, "construction professionals", "civil engineers", and "structural engineers"; (2) for outcomes, "burnout", "exhaustion", "well-being", and "mental-health". Theses and dissertations were excluded. To identify the literature unavailable in journal databases, such as government reports and articles presented at seminars or symposiums, snowball searching was repeatedly performed using the Google Scholar search engine.

The fourth stage is extracting for realist review. The period of extraction for the realist review was until March 2020. The search process discovered 1,147 potential articles for the analysis. After eliminating 247 theses/dissertations or duplicates, an additional 859 studies that did not meet the inclusion criteria were eliminated after reviewing the titles. The remaining 41 articles were reviewed for determining the causes of burnout.

The final stage is data synthesis stage, where selected studies were analysed according to their key variables, which were classified into context, mechanism, and outcomes. As a consequence, 41 actual job-related burnout causes were determined as depicted in Table 1.

\subsection{Design of measuring instrument}

Based on a review and analysis of previous studies on burnout in the construction industry, a questionnaire was composed and distributed among civil engineers at construction sites. The prepared questionnaire comprised three parts for measuring the required variables. The first part was designed through research works based on the literature review and by considering the job demands and lack of various job resources. Section one of the questionnaire was intended to obtain data about the respondents' perception of the causes of burnout. Forty-one influencing causes were identified and related questions were included in this section. The participants were requested to rate the forty-one job-related burnout causes that may affect their burnout level on a five-point Likert scaling for the responses ranging from $1=$ Never to $5=$ Always.

It is possible to find different methodological studies and models on burnout in the literature. The inventories to measure burnout vary correspondingly. The most frequently used burnout inventory is the Maslach Burnout Inventory, Professional Quality of Life Scale (ProQoL) (Stamm, 2005), Copenhagen Burnout Inventory (Kristensen et al., 2005), and Oldenburg Burnout Inventory (Demerouti and Bakker, 2008). Although all the models classify burnout in different ways, their aims are similar. Since the Maslach Burnout Inventory (MBI) was originally designed for use among occupational groups, including those working in jobs such as customer service, maintenance, manufacturing, management, and most other professions in social works (e.g. construction professionals) and has been found to obtain reliable scores in measuring burnout (Maslach et al., 1996), MBI was chosen to assist 
the current research. Maslach Burnout Inventory-General Survey (Maslach et al., 1996) was used as an instrument to measure burnout in the second section. This inventory consists of 16 items and three subscales assessing emotional exhaustion (EE), cynicism (CY), and professional inefficacy (PIE). This well-validated 16-item scale uses seven-point Likert scaling for responses ranging from $1=$ Never to $7=$ Every day.

The last part focused on obtaining data regarding the personal and socio-demographical properties of the respondents. This section contains four questions regarding gender, age, marital status, and education.

\subsection{Data collection and participants}

The target population for this research included civil engineers who are working at construction sites in Turkey.

Prior to the main survey, a pilot survey was carried out. The primary aim of the pilot survey was to check the clarity of the questions to eliminate difficulties and confusing statements in the wording and estimate the length of the time that a participant would take to complete the questionnaire. A pilot survey was conducted by distributing ten questionnaires to civil engineers who have more than 5 years of experience in construction sites in Turkey. Based on the comments and the suggestions obtained from the pilot survey, the final version of the questionnaire was prepared.

The main questionnaires were provided to 786 civil engineers at construction sites directly and via e-mail from 01 March-15 April 2020. A total of 480 completed questionnaires were returned, representing a response rate of $61.6 \%$.

The age of the participants ranged from $23-60$ years and included both males and females. A total of 206 (42.9\%) participants were $23-30$ years of age; $128(26.7 \%)$ were $31-38$ years old, $64(13.3 \%)$ were $39-46$ years old, $32(6.7 \%)$ were $47-57$ years old, and $50(10.4 \%)$ participants were 55-60 years old. Of the total participants, $440(91.7 \%)$ were males. This distribution is an indicator of the current condition of the Turkish construction industry, which is evidently male-dominated. The sample included $210(43.8 \%)$ single and $270(56.3 \%)$ married civil engineers at construction sites. Classifying participants according to their education level, it was observed that most of the civil engineers $(80.4 \%)$ had a bachelor's degree; $19.6 \%$ of them had a postgraduate degree.

\subsection{Data analysis protocol}

The responses of the participants were coded and analysed using the Statistical Package for Social Sciences (SPSS) v. 22.0 and LISREL v. 8.7.

SPSS was used to conduct various statistical tests including reliability analysis and Exploratory factor analysis (EFA).

Reliability should be measured to determine the internal consistency between questions when using the Likert scale (Nunnally and Bernstein, 2007). By using Likert-scale questions in the first and second part of the questionnaire, the Cronbach's Alpha $(\alpha)$ coefficient was used to determine the statistical reliability and validity of the participants' responses. The $\alpha$ coefficient values ranged between 0 and 1 . According to Cronbach (1951), Tavakol, and Dennick (2011), 0.7 represents the minimum acceptable reliability threshold. To ensure the internal consistency of each measurement scale, Cronbach's Alphas were determined separately.

One of the main objectives of this research was to identify the underlying factor structure. The responses of the 41 reliable burnout causes included in the questionnaire were accordingly inputted into the SPSS software and subjected to an exploratory factor analysis (EFA) using varimax rotation (eigenvalue $=1$ cut-off) to identify the main factors. The items with a factor loading greater than 0.4 were determined to be the main factors (Nunnally and Bernstein, 2007). 
The index of relative importance (IRI) was determined by taking into consideration the participants' responses according to their level of burnout. The IRI was calculated for each cause accounting for each specific set of perception level of the respondents using Eqn (1) (Zhao and Chen, 2018):

$$
\operatorname{IRI}_{k}(\%)=\frac{5\left(n_{5}\right)+4\left(n_{4}\right)+3\left(n_{3}\right)+2\left(n_{2}\right)+n_{1}}{5\left(n_{5}+n_{4}+n_{3}+n_{2}+n_{1}\right)} \times 100
$$

where $\operatorname{IRI}_{k}(\%)$ represents the perception of burnout causes and is calculated separately for each corresponding set $(k)$ of respondents, in which $k$ indicates the burnout level (when the level of burnout is extremely low, $k=1$; when it is at a low level, $k=2$; when it is at a medium level, $k=3$; when it is at a high level, $k=4$; and when it is at an extremely high level, $k=5$ ); and $n 1, n 2, n 3, n 4$, and $n 5$ are the number of questionnaire respondents for marking " 1 " for a very low effect, “ 2 ” for a low effect, “ 3 ” for an average effect, "4" for a high effect, or " 5 ” for a very high effect, respectively.

Therefore, the overall IRI for each item for all the respondents was calculated considering all sets of the level of burnout as a weighted average of the $\mathrm{IRI}_{k}$ obtained from Eqn (1) (El-Gohary and Aziz, 2014) as follows:

$$
\text { Overall IRI }(\%)=\frac{\sum_{k=1}^{k=5}\left(k x \mathrm{IRI}_{k}\right)}{\sum_{k=1}^{k=5} k} \times 100
$$

where Overall IRI (\%) is the total weighted average percentage of the IRI of each item, calculated based on all sets of participant level of burnout; and $\mathrm{IRI}_{k}$ is calculated separately from Eqn (1). In addition, the factor index was calculated using the average IRI of the items in each factor.

In the fifth part of the data analysis, a confirmatory factor analysis (CFA) was conducted on factors causing burnout that were obtained by EFA using the LISREL software. CFA is a type of SEM that is used specifically for measurement models, that is, the relationships between the observed measures or indicators (e.g. test items, test scores, behavioural observation ratings) and latent variables or factors (Brown and Moore, 2012).

Finally, a structural equation model was set up using the LISREL software to evaluate the effectiveness of the determined factors in predicting burnout. The hypothetical model and a structural model are the two significant components of structural equation models that concern how effectively various exogenous variables measure as compared to latent variables. The hypothetical model incorporates estimates of errors of measurement of exogenous variables and their intended latent variables within a structural equation model (Green, 1990). The second constituent of the structural equation model is the structural model. The structural equation models can explicitly model direct, indirect, or correlative effects, different from the standard regression models. Emphasising an occurrence or process is the structural component of the structural equation models that permits researchers to derive essential assertions regarding the relationships between the mechanisms and latent variables (Meyers et al., 2006).

According to Molenaar et al. (2000), satisfying the requirement of the standard indices of the model fit (such as $t$-statistics and $R$-squares for model equations) is necessary to set up the final structural model. On the other hand, the findings may be immature and raw based on theoretical prediction, previous observations and empirical findings. Based upon the recommended goodness of fit (GOF) measures, a feasible model should be selected and the model that satisfies both the theoretical expectations and GOF is finally selected for the SEM 
analysis (Molenaar et al., 2000). Therefore, in this study, the model was improved to enhance the fit to its recommended levels by employing GOF measures.

To measure the adequacy of the model with respect to the relationship between the latent variables and the underlying standardised loadings of the measurement paths, the SEM analysis is usually a reasonable assessment method of the reliability measure.

There is no certain rule in the literature about the lower bound value required for the path coefficient to be considered significant. According to Chin (1998) and Lohmöller (1989) path coefficient above 0.1 is stated to be satisfactory, and the ideal value is recommended to be above 0.2 . The path coefficients equal to or above 0.5 and a $t$-value of more than 2.58 was accepted to be significant at $99.0 \%$ confidence level in the current study (Jöroskog and Sörbom, 1993).

\section{Results}

\subsection{Reliability and validity of questionnaire results}

The Cronbach $\alpha$ coefficients that measure the reliabilities of the data set for the 41 burnout causes and Maslach Burnout Inventory was determined to be 0.986 and 0.904, respectively, which are above the minimum threshold of 0.7 (Tavakol and Dennick, 2011). These values indicate excellent internal consistency of the responses.

\subsection{Burnout score analysis}

The scores of three dimensions of burnout for each subscale were provided separately and not combined into a single, total score to identify the burnout levels of civil engineers at construction sites. The scores of the three dimensions were computed independently (Maslach et al., 1996). The burnout scores of the participants are given in Table 2.

Based on data in Table 2 , it can be clearly seen that civil engineers working at construction sites experienced high levels of emotional exhaustion and cynicism, and moderate levels of professional efficacy.

\subsection{Means and ranking of causes inducing burnout among civil engineers at construction sites}

One of the aims of the current research is to identify the causes with the greatest effect on the burnout among civil engineers at construction sites. The mean and rank orders of the identified 41 causes are derived from the total sample to obtain their level of importance. Table 3 presents the mean ratings and respective rankings of 41 causes of burnout. Should two or more causes have the same mean scores, the cause with the lower standard deviation (SD) is deemed more important.

In all, BC5 "Having the job done for people who are not competent at the lowest prices", $\mathrm{BC} 40$ "The intervention and disrespect of the profession by individuals outside the profession", BC39 "The high number of colleagues who do the same job almost without making money", BC6 "Payment delays" and BC7 "Absence of penalties for delayed

\begin{tabular}{|c|c|c|c|c|}
\hline \multirow[b]{2}{*}{ MBI-general survey } & \multicolumn{4}{|c|}{ Sample means ${ }^{\mathrm{a}}(\mathrm{SD})$} \\
\hline & $\begin{array}{l}\text { Number of } \\
\text { participants }\end{array}$ & $\begin{array}{l}\text { Emotional } \\
\text { exhaustion }\end{array}$ & Cynicism & $\begin{array}{c}\text { Professional } \\
\text { inefficacy }\end{array}$ \\
\hline $\begin{array}{l}\text { Construction site civil } \\
\text { engineers }\end{array}$ & 480 & $4.70(0.99)$ & $4.36(0.97)$ & $3.26(0.77)$ \\
\hline
\end{tabular}

\author{
Critical \\ predictors of \\ burnout
}




ECAM

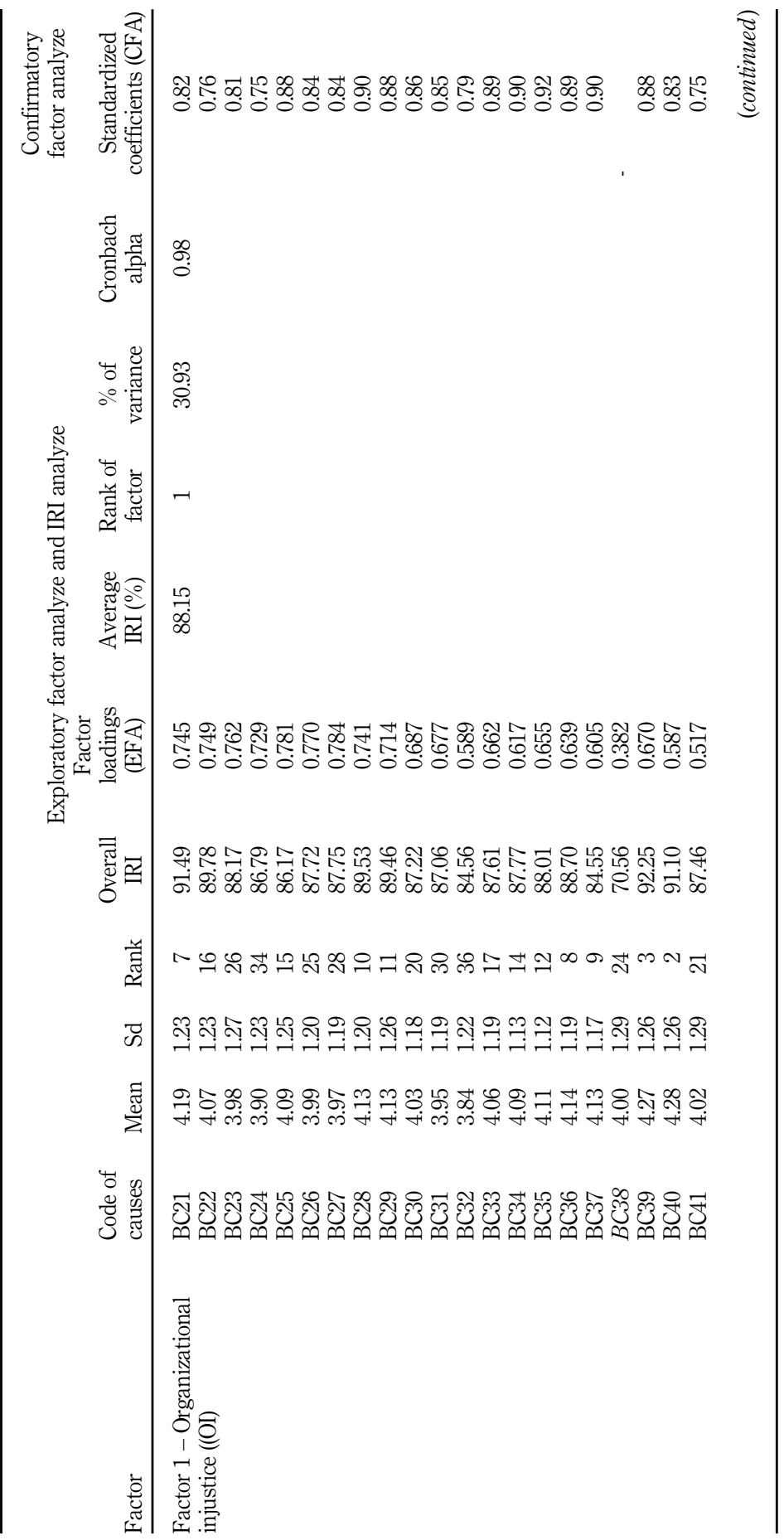

Table 3.

Exploratory and confirmatory factor analysis results 


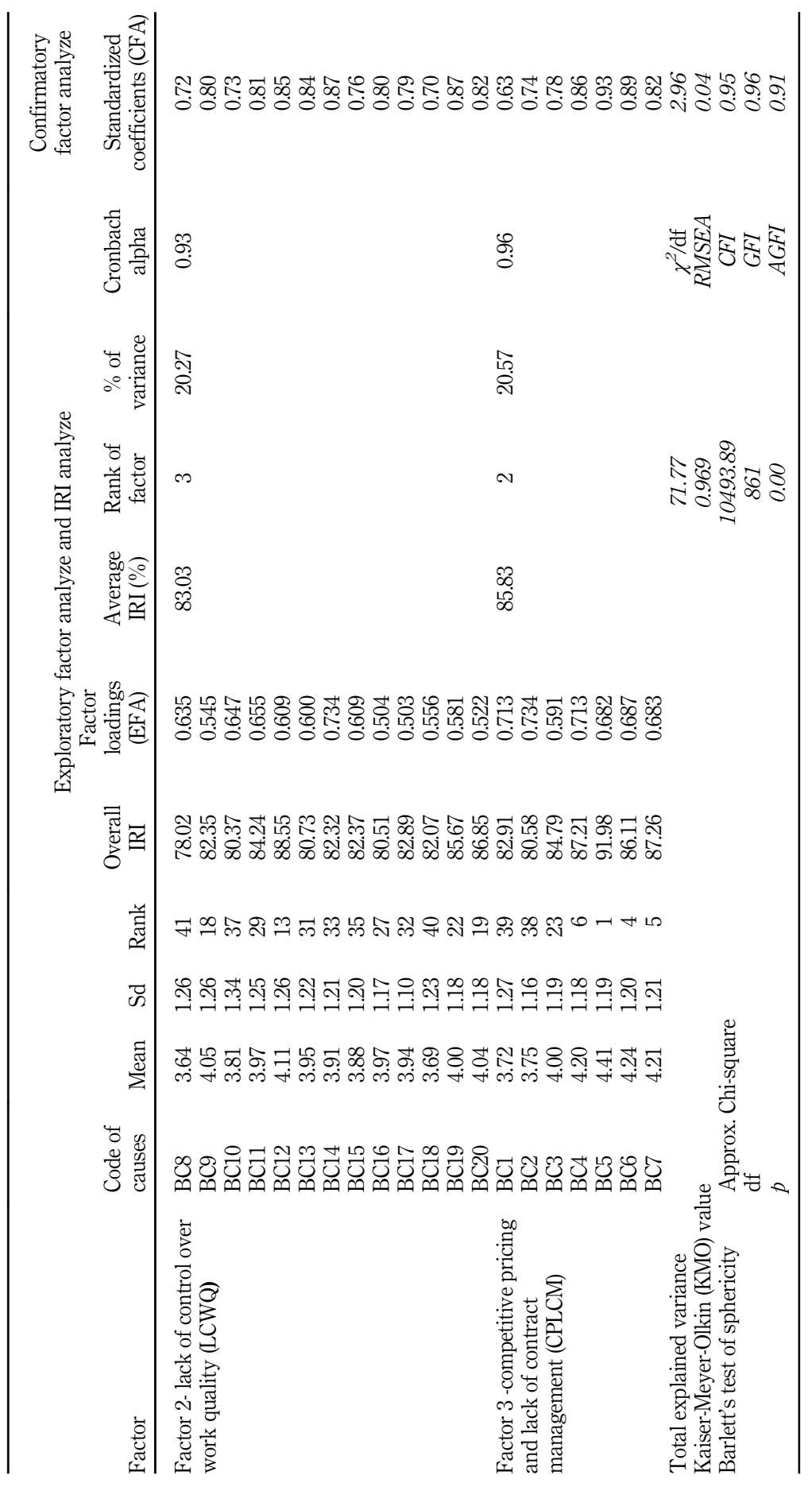

Critical predictors of burnout

Table 3. 
payments" are the top five critical causes inducing burnout among civil engineers at construction sites.

\subsection{Underlying factors causing burnout among civil engineers at construction sites - EFA}

As one of the main aims of this research is identifying the factors causing burnout, the underlying factor structure is important. The main goal of the EFA is to reduce the number of variables/causes with a minimum loss of information and to detect the structure of the relationships between these variables (Hair et al., 1992). In this research, the principal component method of extraction was used for the EFA, and the Kaiser normalization of rotation for varimax was used. The principal components analysis aimed to mathematically derive a relatively small number of variables to convey as much information as possible regarding the forty-one considered causes of burnout for civil engineers working at construction sites.

Table 3 demonstrates the results of the EFA. As can be seen, majority of the causes load onto appropriate factors. Due to it exhibited factor loadings less than 0.4, one item (Code of factor number BC38 demonstrated in italics in Tables 1 and 3) was removed from the questionnaire responses in the data set. Thus, forty items that were obtained together with their coefficient alpha reliabilities are summarised in Table 3 (Tabachnick and Fidell, 2001).

The Kaiser-Meyer-Olkin (KMO) value for sampling adequacy is 0.969 , which is greater than 0.5 and indicating that the data set is suitable for factor analysis (Pallant, 2005). The Bartlett's test of sphericity, a statistical test used to investigate the presence of correlations among the variable, provided a result of 10493.89 with an associated significance level of 0.00 , suggesting that the population correlation matrix is not an identity matrix. Three components representing factors with an eigen value greater than 1 were then extracted and they accounted for $71.77 \%$ of the explained total variance. Each of these components was then interpreted, labelled, and coded as follows:

(1) Factor 1: Organisational Injustice (OI)

(2) Factor 2: Lack of Control Over Work Quality (LCWQ)

(3) Factor 3: Competitive Pricing and Lack of Contract Management (CPLCM)

Finally, the exploratory factor analysis results of the forty causes with their Cronbach's alpha coefficient reliabilities are summarised in Table 3. Cronbach's alpha for each scale (reported as Table 3$)$ ranges from 0.93 to $0.98(\alpha>0.600)$, indicating excellent scale reliability.

\subsection{Results of factor ranking}

The factor model describing the biggest factors affecting the cause of the burnout among the civil engineers at construction sites herein is based on the three factors resulting from the analysis in Section 4.4. Using the IRI analysis detailed in Section 3.4, the relative importance of each factor was ranked as presented in Table 3, with the importance decreasing from organisational injustice, lack of control over work quality, competitive pricing, and lack of contract management (from $88.15 \%$ to $83.03 \%$ ). Therefore, based on the influencing factor model, organisational injustice was determined to be the most significant reason for burnout among the civil engineers at construction sites in Turkey.

\subsection{Burnout factors interrelationships}

The interrelationships of factors that cause burnout were analysed using correlation analysis. The inter-correlations within the three factors are given in Table 4 . Remarkable positive correlations (significant at $p \leq 0.01$ ) are found between. 
(1) Organisational injustice and Lack of control over work quality (0.898)

Critical

(2) Organisational injustice and Competitive pricing and lack of contract management $(0.820)$

(3) Lack of control over work quality and Competitive pricing and lack of contract management (0.836).

\subsection{Confirmatory factor analysis}

A confirmatory factor analysis (CFA) is used to test whether measures of a construct are consistent with the understanding of the nature of that factor (Kline, 1998). In other words, the main aim of CFA is to analyse whether the data fit a hypothesised measurement model. In the current research, the LISREL 8.7 software was used for this purpose. The model fit indices $\left(\chi^{2} / \mathrm{df}\right.$, goodness of fit index "GFI", adjusted goodness of fit index "AGFI", and comparative fit index "CFI") that were employed to test the fitness of the proposed model; further details of these indices can be found in Mandujano et al. (2017) and Fotopoulos and Psomas (2010). The suggested values of the model's goodness-of-fit test are shown in Table 5 and the related values are presented in Table 3.

The results of the CFA are reported in Table 3; all of the loadings of the causes exceed 0.6 as shown. In addition, the model is satisfactory based on the goodness-of-fit indices proposed in this research: the value of $\chi^{2} / \mathrm{df}$ is 2.96 , the CFI is 0.95 , the root mean square error of approximation "RMSEA" is 0.04 , and the GFI is 0.96 , all suggesting a good model fit. Based on these model fitness ratios, it can be confidently reported that the CFA model provides a good fit and can be used for validity testing of the measurement scales. Therefore, the results indicate that all of the items and factors contained in the hypothetical model are considered reliable, and SEM could be used to test the theoretical model.

\subsection{Structural equation modelling}

In order to investigate the relationship between the main factors of burnout and burnout dimensions among civil engineers at construction sites, an integrated structural equation model was developed using LISREL 8.7. A conceptual model of the main factors that cause burnout on burnout sub-dimensions is proposed and shown in Figure 1. Each path of the model presents a hypothetical relationship between a pair of constructs.

\begin{tabular}{|c|c|c|c|c|}
\hline & OI & LCWQ & CPLCM & \\
\hline OI & 1 & & & \\
\hline LCWQ & $0.898^{* * *}$ & 1 & & \\
\hline CPLCM & $0.820 * *$ & $0.836^{* *}$ & 1 & Correlation amongst \\
\hline \multicolumn{4}{|c|}{ Note(s): $* *$ Correlation is significant at the 0.01 level (2-tailed) } & burnout factors \\
\hline
\end{tabular}

\begin{tabular}{|c|c|c|c|c|}
\hline Fit index & Suggested values & Structural equation results & Evaluation & \\
\hline$X^{2} / \mathrm{df}$ & $0 \leq X^{2} / \mathrm{df} \leq 3$ & 2.87 & Good & \\
\hline GFI & $0 . \overline{95} \leq \mathrm{GFI} \leq 1.00$ & 0.95 & Good & \\
\hline AGFI & $0.95 \leq \mathrm{AGFI} \leq 1.00$ & 0.96 & Good & \\
\hline RMSEA & $0 \leq \overline{R M S E A} \leq 0.05$ & 0.04 & Good & Table 5. \\
\hline CFI & $0 . \overline{95} \leq \mathrm{CFI} \leq 1.00$ & 0.97 & Good & Summary statistics of \\
\hline NFI & $0.95 \leq \mathrm{NFI} \leq 1.00$ & 0.96 & Good & model fitness indices \\
\hline
\end{tabular}




\section{ECAM}

Figure 1.

Hypothetical model of the predictors of the burnout among civil engineers at construction sites

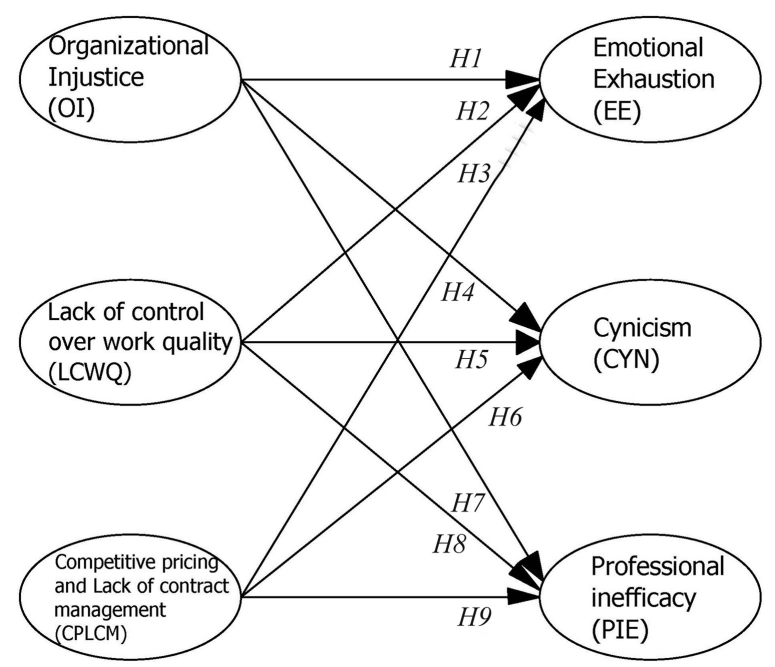

It is hypothesised that the factors that cause burnout (OI, LCWQ, and CPLCM) affect the burnout sub-dimensions (Emotional exhaustion "EE", Cynicism "CYN", Professional inefficacy "PIE") among civil engineers at constructions sites.

To examine the main effects of these 3 main burnout factors on the burnout levels, the following nine hypotheses were established as follows (paths in Figure 1):

H1. OI has a positive correlation with Emotional exhaustion.

H2. LCWQ has a positive correlation with Emotional exhaustion.

H3. CPLCM has a positive correlation with Emotional exhaustion.

H4. OI has a positive correlation with Cynicism

H5. LCWQ has a positive correlation with Cynicism.

H6. CPLCM has a positive correlation with Cynicism.

H7. OI has a positive correlation with Professional inefficacy.

H8. LCWQ has a positive correlation with Professional inefficacy.

H9. CPLCM has a positive correlation with Professional inefficacy.

The paths of the model were measured according to the different signs, sizes, and statistical significances of the path coefficients among the variables. The higher the path coefficient, the stronger is the relationship between the independent and dependent constructs of a path. The significance of the hypothesised associations was examined by evaluating the significance of the $t$ values. Tables 5 and 6 (also see Figure 2) summarise all the parameters used in the validation process of the model.

Associated with hypothesised model shown in Figure 1, the final structural equation model is presented in Figure 2 along with the standardised path coefficients of the structural paths. The significant levels of the path are labelled and the rejected paths are shown using light dotted lines.

In addition, the accepted model has a relatively high level of fitness, as shown in Table 5. According to the values in this table, the model developed for the burnout among the civil 
engineers at construction sites fits based on the required GOF measures and could perform satisfactorily. Both the goodness of fit index (GFI) value of 0.95 and the ratio of $\chi^{2} /$ degrees of freedom of 2.87 are within the acceptable range. The root means square error of approximation (RMSEA) value of 0.04 at $p<0.05$ shows that the final model cannot be rejected with a high level of confidence (Table 5). Furthermore, other necessary indicators such as the comparative fit index $(\mathrm{CFI}=0.97)$ and the normed fit index $(\mathrm{NFI}=0.96)$ contribute to accepting the fit between the data and the measurement model (Molenaar et al., 2000).

Table 6 summarises the hypothetical paths and assumed effects, standardised path coefficients, and the signs of the hypothesised paths. Using the $t$-test values, the significance of the path coefficients was analysed. To determine the one-way impacts of one factor over another, the one-tailed significance $(p<0.01)$ method is used (Field, 2005).

As seen in Figure 2 and Table 6 , four of nine hypotheses could be proved at the acceptable significance level of $p<0.01$, and $t$-values $>2.58$, which indicates a $99.0 \%$ confidence level. Table 6 indicates that OI $(0.93,0.99)$ has the most significant effect on the emotional exhaustion and cynicism of the civil engineers at construction sites, followed by CPLCM $(-0.48,-0.45)$. It is remarkable that LCWQ has no effect on burnout sub-dimensions. Furthermore, none of the burnout factors impact the professional inefficacy dimension of burnout.

\section{Discussion}

This study set out to examine the factors affecting the burnout levels of civil engineers at construction sites. Findings in the literature regarding the burnout of construction professionals are generally associated with relationships between burnout and other variables (turnover intention, safety performance, work-family conflict etc.). Therefore, determining the most important factor/factors that cause burnout is significant. In addition, how the identified factors the burnout sub-dimensions are vital.

\subsection{Causes affecting the burnout among civil engineers at construction sites}

As presented in Table 3, the most frequently identified cause affecting the burnout among civil engineers at construction sites is "Having the job done for people who are not competent at the lowest prices". This finding is consistent with the results of Poon et al. (2013) and Ibem et al. (2011), in that they determined competitor pricing cascades the level of construction professionals' burnout.

\begin{tabular}{|c|c|c|c|c|}
\hline Hypothetical paths and expected influences & Path coefficient ${ }^{\mathrm{a}}$ & $t$-value (1-tail) & Interpretation & \\
\hline$H 1: O I \rightarrow E E$ & +0.93 & +6.07 & Supported & \\
\hline $\mathrm{H} 2: \mathrm{LCWQ} \rightarrow \mathrm{EE}$ & -0.20 & -1.23 & Not supported & \\
\hline H3: $C P L C M \rightarrow E E$ & -0.48 & -3.85 & Supported & \\
\hline$H 4: \mathrm{OI} \rightarrow \mathrm{CYN}$ & +0.99 & +5.49 & Supported & \\
\hline H5: LCWQ $\rightarrow$ CYN & -0.34 & -1.81 & Not supported & \\
\hline H6: $C P L C M \rightarrow C Y N$ & -0.45 & -3.17 & Supported & \\
\hline $\mathrm{H} 7: \mathrm{OI} \rightarrow \mathrm{PIE}$ & +0.21 & +1.25 & Not supported & \\
\hline H8: LCWQ $\rightarrow$ PIE & -0.14 & -0.76 & Not supported & $\begin{array}{r}\text { Table } 6 . \\
\text { Standardizd }\end{array}$ \\
\hline H9: CPLCM $\rightarrow$ PIE & +0.08 & +0.64 & Not supported & $\begin{array}{l}\text { Standardized } \\
\text { coefficient estimates }\end{array}$ \\
\hline \multicolumn{5}{|c|}{ 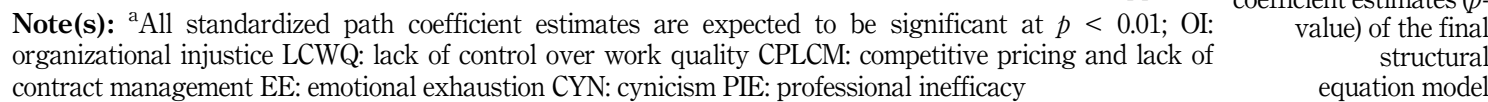 } \\
\hline
\end{tabular}

\section{Critical predictors of burnout}




\section{ECAM}

Figure 2.

Final structural equation model of burnout predictors and burnout subdimensions

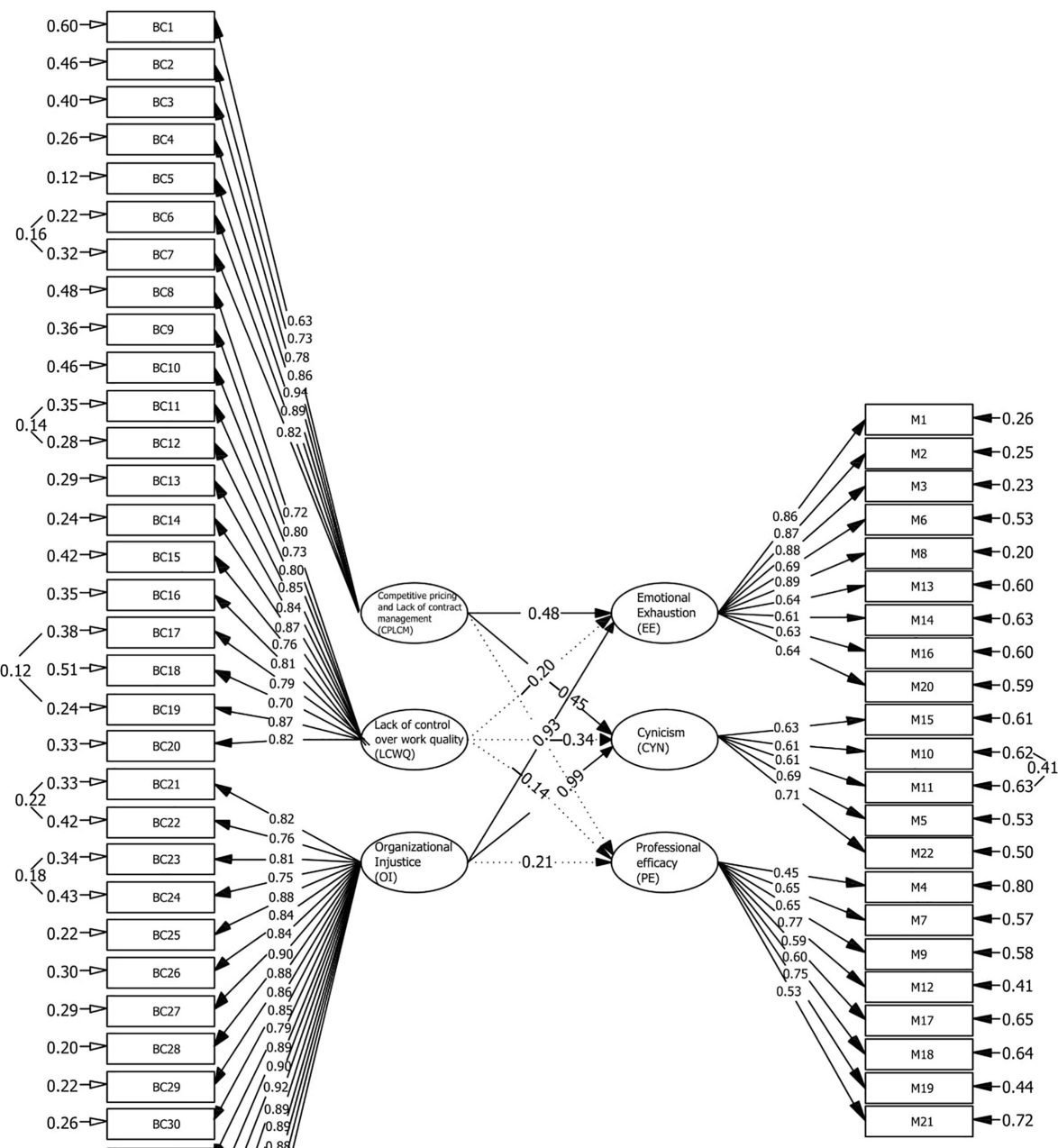

Chi-Square $=5188.96$

$\mathrm{df}=1808 \quad p$-value $=0.000$

RMSEA $=0.04$ 
5.2 Factors influencing the burnout among civil engineers at construction sites

This study developed and validated a framework for exploring and assessing factors that most significantly affect the burnout of civil engineers at construction sites. The three latent factors that mostly affect the burnout level of civil engineers at construction sites determined by the EFA and CFA, that are detailed in sections 4.4. and 4.7, are discussed in detail in this section.

5.2.1 Organisational injustice (OI). The factor OI is ranked first out of the three critical factors causing burnout among civil engineers at construction sites, with $88.15 \%$ average IRI, indicating that organisational injustice plays a dominant and vital role (Table 3).

Unfairness in rewards/promotions and work overload are two core circumstances for organisational injustice. The correlation between burnout and work overload has been identified in previous literature (Cordes and Dougherty, 1993; Maslach et al., 2001) and was further confirmed for construction professionals in a former research work by Sun et al. (2020). The current research demonstrated that work overload is not enough for civil engineers at construction sites to experience a high level of burnout. The combination of unfairness in rewards/promotions and salary with work overload cause a high level of burnout. This finding is consistent with that of Sun et al. (2020) that determined that the absence of fairness and perceived workload affect construction professionals' burnout in China that proves the relationship between job resources and job demands. As explained by Demerouti et al. (2001), job resources (lack of fairness in rewards and salaries) or job demands (work overload) individually is less likely to cause burnout; however, while these factors merge, they cause a high level of burnout.

"The high number of colleagues who do the same job almost without making money" and "Salaries of the employees in the same job position are unequal and unfair" causes, which has an IRI of $92.25 \%$ and $91.49 \%$, respectively, was ranked first and second among the OI factors.

5.2.2 Lack of control over work quality (LCWQ). Of the three factors in the model, the LCWQ was ranked third based on the result of the IRI analysis. There are thirteen causes within this factor, one of which (Considering the building inspection as a formality) tied as the most important cause with IRI at $88.55 \%$.

Quality management has been widely used by world-class companies to ensure successful project delivery in a construction project (Aichouni et al., 2014). Quality needs control, which is specifically implemented by the quality assurance program. Effective control for quality reduces the possibilities of change, mistakes, and omissions, which in turn result in fewer conflicts and disputes. Most of the engineers were in total control during the construction phase when they carried out a role described as "supervision," ensuring that the owner received his money's worth in terms of quality. Although quality control has been widely implemented in the developed countries (e.g. Japanese, American construction industry), it has not yet been implemented successfully in developing countries (Abdel-Razek, 1998; Hiyassat, 2000; Kazaz et al., 2004; Abdel-Salam and Gad, 2009). Based on the research results of Kazaz and Birgonul (2005), Turk (2006) and Haseeb et al. (2011), construction firms have some deficiencies in getting stability in a quality concept when their business structures use temporary labourers and change their location constantly and consequently. These quality control deficiencies affect not only the delivery time, budget, profitability, and standards of quality expected (Love et al., 2000), but also, the burnout levels of civil engineers at construction sites.

5.2.3 Competitive pricing and lack of contract management (CPLCM). Competitive pricing and lack of contract management (CPLCM) factor ranked second among three factors with an IRI of $85.83 \%$. Having the job done for people who are not competent at the lowest prices ranked as the most important cause in this group with an IRI of $91.98 \%$. This result agrees with the former study of Poon et al. (2013) where they stated that the negative impact of competitive pricing manifests as insufficient allocation of resources in the management of the contraction
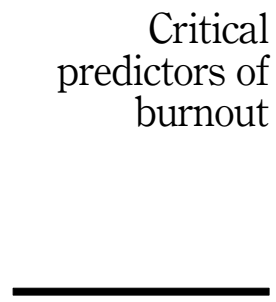
process. In the current research, competitive pricing is coupled with the lack of contract management, leading to burnout of civil engineers at construction sites. Murdoch et al. (2008) remarked that the inclination of a big part of owners to reflect various risks in the contract, in effect transferring those risks to contractors, leads to an increasing number of contractors employing systematic contract management. With judicious contract management, risk transferred should be defused throughout the project stages. However, this is not usually the case. Contract management should be carried out throughout the project, and each stage of contract management has its precedence and its particular tasks (Dai, 2009). According to Dai (2009), contract management has two stages named as the establishment of the contract and implementation of the contract. Contract management is an important issue for the productivity of the construction process. Former studies explored the mentioned issue in the context of construction organisations. With this research finding, lack of contract management has negative effects not only on the organisation but also on the construction site workers.

5.2.4 Burnout predictors of civil engineers at construction sites. The current study validates the MBI-general Survey in measuring burnout scientifically considering emotional exhaustion, cynicism, and professional inefficacy with high internal consistency and reliability.

In the current research, civil engineers at construction sites experience severe burnout, particularly, with respect to emotional exhaustion and cynicism. This result demonstrates consistency with Yip and Rowlinson's (2009) result. Although numerous empirical studies have been conducted to search this phenomenon in highly stressful working environments, such as the education sector, healthcare, limited systematic quantification of the causes of burnout in the construction industry is a significant issue. Moreover, there is not any research on this phenomenon in the Turkish construction industry. Since burnout is associated with employees' physical and mental disorders, decreased effectiveness, satisfaction, organisational commitment, and turnover intention, burnout is an important concern for the construction industry (Leither and Maslach, 1988; Maslach et al., 2001; Toppinen-Tanner et al., 2005).

Burnout has a negative impact on organisational effectiveness and industrial productivity (Wright and Bonnet, 1997). The findings of this research prove that the high level of stress imposed on civil engineers at construction sites are likely to cause noticeable negative impacts on both individuals and organisations.

5.2.4.1 Predicting emotional exhaustion. Approximately, forty-two percent of variations in emotional exhaustion can be explained by the model $\left(R^{2}=0.419\right)$. Significant strong predictors of emotional exhaustion include organisational injustice $(+0.93$ path coefficient) and competitive pricing and lack of contract management (-0.48 path coefficient). Whereas lack of control over work quality ( -0.20 path coefficient) has no effect on the emotional exhaustion of civil engineers at construction sites. Although there are limited researches on this, there is no similar study using this method. Therefore, comparisons of the current research results and former studies were done with existing outcomes. These results show consistency with the results of Lingard (2003) and Yip et al. (subject 2005, 2008). The effect of organisational injustice in causing emotional exhaustion is significant. Although to a lesser extent, competitive pricing and lack of contract management is also a significant predictor of burnout among civil engineers at construction sites.

5.2.4.2 Predicting cynicism. Almost forty percent of variations in cynicism can be explained by the model $\left(R^{2}=0.398\right)$. Significant strong predictors of cynicism included organisational injustice (+0.99 path coefficient), and competitive pricing and lack of contract management (-0.45 path coefficient). Similarly, at predicting emotional exhaustion, lack of control over work quality ( -0.34 path coefficient) has no effect on cynicism. This result agrees with that of Lingard (2003)'s and Poon et al. (2013) stating that competitive pricing is an 
important cause for burnout of a construction professional. When the results are compared, it is clearly seen that Poon et al. (2013) identified the mentioned predictor as a conclusion of the interviews with professionals, the existence of the predictor is presented with literature review and tested with the questionnaire. The strength of the predictor is proved statistically in the current research. Lingard (2003) stated that job-related variables are significant predictors for cynicism. When the context of organisation injustice is examined (as stated in section 5.2.1), this predictor is a combination of job-related and job-demand variables. Therefore, it is proven with the current research results that not only job-related but also jobdemand variables are important predictors of cynicism.

5.2.4.3 Predicting professional inefficacy. Only almost ten percent of variation in personal efficacy can be explained by the model $\left(R^{2}=0.095\right)$. The extremely low value of $R^{2}$, path coefficients, and t-values indicate that none of the three predictors explain the cause of professional inefficacy. This result strings together other findings of this research. The level of professional inefficacy of the civil engineers at construction sites is extremely low. Therefore, the nonexistence of a predictor is of little wonder.

When the predictors are evaluated overall, organisational injustice, and competitive pricing and lack of contract management are significant predictors of burnout among civil engineers at construction sites in Turkey.

\section{Conclusions, contributions and limitations}

Civil engineers employed at construction sites play a significant role in ensuring coordination, planning, arrangement of workforce, machines and materials, supervision, control of progress, quality, and budget, as well as compliance with legal requirements in terms of safety and environmental issues. Due to the multidimensional and complex nature of work, civil engineers at construction sites often operate in stressful environments.

The current study investigates the critical factors that affect the burnout among civil engineers at construction sites in the Turkish construction industry using a multistage methodological framework. At the first stage, 41 causes were identified with the realistic review method considering the nature of the working environment associated with the burnout among civil engineers at construction sites. Grounding these causes three critical factors, including organisational injustice, competitive pricing and lack of contract management, and lack of control over work quality were determined by exploratory factor analyses at the second phase. Finally, by using LISREL 8.7. software package, critical predictors of emotional exhaustion, cynicism, and professional inefficacy were identified.

The current empirical study found that civil engineers at construction sites have high levels of burnout, especially, due to emotional exhaustion and cynicism in the Turkish construction industry. Organisational injustice, competitive pricing and lack of contract management, and lack of control over work quality were determined as the critical factors that affect the burnout among civil engineers at construction sites. These three factors are connected to each other. Organisational injustice is the most significant antecedent of emotional exhaustion and cynicism; competitive pricing and lack of contract management is the other significant predictor. As a result, civil engineers at construction sites do not suffer from professional inefficacy. Thus, there is no predictor of this dimension. These results produced evidence for impacts of each factor on the burnout dimensions.

The current study represents the first comprehensive determination of the factors that affect the burnout dimensions and makes three-fold theoretical contributions. First, this study determines various causes considering both the job demand and job resources. Second, critical influencing factors of burnout are determined, which are specific to civil engineers at construction sites. Third, burnout-subdimensions model of civil engineers at construction sites is formed, which helps to explain why the level of emotional exhaustion and cynicism 
levels of civil engineers are high. This model helps to understand the relationship between burnout dimensions and its predictors.

This research also provides managerial implications for practitioners, including directors, managers, and construction professionals. First, in order to minimise the burnout level, managers and employers should be fair to all employees. Second, job redesign may be an effective prevention strategy to decrease the negative effects of burnout.

The current study has some limitations within the context of a sample as exploring the civil engineers who only work at construction sites. Further researches may examine the civil engineers employed in offices. Moreover, the structural model of the current study has a good fit; further studies may delve into the mediator effect of demographical variables. It is important to note that this study was limited because it employed a generic approach to determine the factors that cause burnout in construction sites in Turkey; it should be understood that these factors are sensitive to the specific conditions of the region in which a project is located as well as the type of project undertaken. As mentioned before, burnout has various effects in both individual and organisational contexts such as depression, a decrease in organisational commitment, turnover etc. What kind of consequences result from determined predictors of burnout may be a topic of research for forthcoming studies.

Finally, civil engineers employed at construction sites play a critical role in completing construction projects successfully. However, the organisational performance of civil engineers at construction sites is worsened as a result of suffering burnout. The sense of belonging of employees and morale are closely related to organisational performance. Construction site civil engineers who have low personal accomplishments and who incline to depersonalise themselves are different from others who have high morale or a clear sense of belonging within an organisation. Organisations should develop systems that will foster the well-being of both the civil engineers at construction sites and all the construction professionals so that they are able to stay healthy and productive. A knowledge of the factors that may cause burnout among the civil engineers at construction sites could forestall burnout. Such a step not only assists the construction firms, but also, the construction industry.

\section{References}

Abdel-Razek, R.H. (1998), "Factors affecting construction quality in Egypt: identification and relative importance", Engineering, Construction and Architectural Management, Vol. 5 No. 3, pp. 220-227.

Abdel-Salam, H.M.E. and Gad, M. (2009), "Cost of quality in Dubai: an analytical case study of residential construction projects”, International Journal of Project Management, Vol. 27 No. 5, pp. 501-511.

Aichouni, M., Messaoudene, N.A., Al-Ghonamy, A. and Touahmia, M. (2014), "An empirical study of quality management systems in the Saudi construction industry", International Journal of Construction Management, Vol. 14 No. 3, pp. 181-190.

Bakker, A.B. and Demerouti, E. (2017), "Job demands-resources theory: taking stock and looking forward", Journal of Occupational Health Psychology, Vol. 22 No. 3, p. 273.

Bakker, A.B., Demerouti, E. and Euwema, M.C. (2005), "Job resources buffer the impact of job demands on burnout”, Journal of Occupational Health Psychology, Vol. 10 No. 2, p. 170.

Brown, T.A. and Moore, M.T. (2012), “Confirmatory factor Analysis”, in Holye, R.H. (Ed.), Handbook of Structural Equation Modelling, The Guilford Press, pp. 361-379.

Chin, W.W. (1998), "The partial least squares approach to structural equation modelling", in Marcoulides, G.A. (Ed.), Modern Methods for Business Research, Lawrence Erlbaum Associates Publishers, New Jersey, NJ, pp. 295-336.

CIOB (2006), Stress in the Construction Industry, CIOB Published National Stress Survey Results, available at: www.ciob.org.uk/resources/publications (accessed 21 June 2007). 
Cordes, C.L. and Dougherty, T.W. (1993), "A review and an integration of research on job burnout", Academy of Management Review, Vol. 18, pp. 621-56.

Cronbach, L.J. (1951), "Coefficient alpha and the internal structure of tests", Psychometrika, Vol. 16, pp. 297-334.

Dai, P., Gan, H. and Gu, Y. (2009), Contract Management for International EPC Projects, Southeast University, Nanjing.

Demerouti, E. and Bakker, A.B. (2008), "The Oldenburg Burnout Inventory: a good alternative to measure burnout and engagement”, Handbook of Stress and Burnout in Health Care, Nova Science Publishers, New York, NY, pp. 65-78.

Demerouti, E., Bakker, A.B., Nachreiner, F. and Schaufeli, W.B. (2001), "The job demands-resources model of burnout", Journal of Applied Psychology, Vol. 86 No. 3, p. 499.

El-Gohary, K.M. and Aziz, R.F. (2014), "Factors influencing construction labor productivity in Egypt", Journal of Management in Engineering, Vol. 30 No. 1, pp. 1-9.

Enshassi, A., El-Rayyes, Y. and Alkilani, S. (2015), "Job stress, job burnout and safety performance in the Palestinian construction industry", Journal of Financial Management of Property and Construction, Vol. 20 No. 2, pp. 170-187.

Field, A. (2005), Discovering Statistics Using SPSS, 2nd ed., Sage, London.

Fotopoulos, C.V. and Psomas, E.L. (2010), "The structural relationships between TQM factors and organizational performance", The TQM Journal, Vol. 22 No. 5, pp. 539-552.

Gallstedt, M. (2003), "Working conditions in projects: perceptions of stress and motivation among project team members and project managers", International Journal of Project Management, Vol. 21, pp. 449-455.

Ghorpade, J., Lackritz, J. and Singh, G. (2011), "Personality as a moderator of the relationship between role conflict, role ambiguity, and burnout", Journal of Applied Social Psychology, Vol. 41 No. 6, pp. 1275-1298.

Green, P.J. (1990), "On use of the EM algorithm for penalized likelihood estimation", Journal of the Royal Statistical Society: Series B (Methodological), Vol. 52 No. 3, pp. 443-452.

Hair, J.F., Anderson, R.E., Tatham, R.L. and Black, W.C. (1992), Multivariate Data Analysis, 3rd ed., Macmillan, New York, NY.

Hampton, P., Chinyio, E.A. and Riva, S. (2019), "Framing stress and associated behaviours at work an ethnography study in the United Kingdom", Engineering Construction and Architectural Management, Vol. 26 No. 11SI, pp. 2566-2580.

Haseeb, M., Xinhai-Lu, L., Bibi, A., Dyian, M. and Rabbani, W. (2011), "Problems of projects and effects of delays in the construction industry of Pakistan", Australian Journal of Business and Management Research, Vol. 1 No. 5, pp. 41-50.

Hinton, M.A. and Hamilton, R.T. (2016), "Competitive tendering and individual behaviour in the construction industry", Construction Management and Economics, Vol. 33, pp. 1-10.

Hiyassat, M.S. (2000), "Applying the ISO standards to a construction company: a case study", International Journal of Project Management, Vol. 18 No. 4, pp. 275-280.

HKIE (2007), "The Hong Kong institution of engineers, qualification and membership", available at www.hkie.org.hk/ (accessed 25 October 2007).

Hobfoll, S.E. (1989), "Conservation of resources. A new attempt at conceptualizing stress", American Psychologist, Vol. 44 No. 3, p. 513.

Hobfoll, S.E. (2001), "The influence of culture, community, and the nested-self in the stress process: advancing conservation of resources theory", Applied Psychology: An International Review, Vol. 50 No. 3, pp. 337-370.

Ibem, E., Anosike, M., Azuh, D.M. and T. (2011), "Work stress among professionals in the building construction industry in Nigeria", Australasian Journal of Construction Economics and Building, Vol. 11 No. 3, pp. 45-57. 
Isik, Z., Arditi, D., Dikmen, I. and Birgonul, M.T. (2010), "Impact of resources and strategies on construction company performance", Journal of Management in Engineering, Vol. 26 No. 1, pp. 9-18.

Janssen, P.P.M., Baker, A.B. and Jong, A.D. (2001), "A test and refinement of the demand-controlsupport model in the construction industry", International Journal of Stress Management, Vol. 8 No. 4, pp. 315-32.

Jöreskog, K.G. and Sörbom, D. (1993), LISREL 8: Structural Equation Modelling with the SIMPLIS Command Language, Lawrence Erlbaum, Hillsdale, New Jerssey, NJ.

Joslin, R. and Müller, R. (2015), "Relationships between a project management methodology and project success in different project governance contexts", International Journal of Project Management, Vol. 33, pp. 1377-1392.

Jugdev, K., Mathur, G. and Cook, C. (2018), "Linking workplace burnout theories to the Project management discipline”, International Journal of Managing Projects in Business, Vol. 11 No. 1SI, pp. 198-221.

Kazaz, A.M. and Birgonul, T. (2005), "The evidence of poor quality in high rise and medium rise housing units: a case study of mass housing projects in Turkey", Building and Environment, Vol. 40 No. 10, pp. 1548-1556.

Kazaz, A., Ulubeyli, S. and Turker, F. (2004), "The quality perspective of the ready-mixed concrete industry in Turkey", Building and Environment, Vol. 39, pp. 1349-1357.

Kazaz, A., Manisali, E. and Ulubeyli, S. (2008), "Effect of basic motivational factors on construction workforce productivity in Turkey", Journal of Civil Engineering and Management, Vol. 14 No. 2, pp. 95-106.

Kim, B.C. and Reinschmidt, K.F. (2011), "Combination of project cost forecasts in earned value management", Journal of Construction Engineering and Management, Vol. 137, pp. 958-966.

Kline, R.B. (1998), Methodology in the Social Sciences, Principles and Practice of Structural Equation Modelling, Guilford Press, New York, NY.

Kristensen, T.S., Borritz, M., Villadsen, E. and Christensen, K.B. (2005), "The Copenhagen Burnout Inventory: a new tool for the assessment of burnout”, Work \& Stress, Vol. 19 No. 3, pp. 192-207, doi: 10.1080/02678370500297720.

Lasota, D., Goniewicz, K., Goniewicz, M. and Czerski, R. (2018), "Analysis of the professional burnout syndrome in selected groups", Journal of Education, Health and Sport, Vol. 8 No. 8, pp. 81-96.

Lee, R.T. and Ashforth, B.E. (1996), "A meta-analytic examination of the correlates of the three dimensions of job burnout", Journal of Applied Psychology, Vol. 81 No. 2, pp. 123-33.

Lee, W., Migliaccio, G.C., Lin, K.Y. and Seto, E.Y. (2020), "Workforce development: understanding task-level job demands-resources, burnout, and performance in unskilled construction workers”, Safety Science, Vol. 123, 104577.

Leiter, M. (1993), "Burnout as a development process: consideration of models", in Schaufeli, M. and Marek (Eds), Professional Burnout: Recent Developments in Theory and Research, Taylor \& Francis, Philadelphia.

Leiter, M.P. and Maslach, C. (1988), "The impact of interpersonal environment on burnout and organizational commitment", Journal of Organizational Behavior, Vol. 9 No. 4, pp. 297-308.

Leiter, M.P. and Maslach, C. (2001), "Burnout and quality in a sped-up world", The Journal for Quality and Participation, Vol. 24 No. 2, pp. 48-60.

Leiter, M.P. and Schaufeli, W.B. (1996), "Consistency of the burnout construct across occupations", Anxiety, Stress, and Coping, Vol. 9 No. 3, pp. 229-243.

Leung, M.Y., Sham, J. and Chan, Y.S. (2007), “Adjusting stressors-job-demand stress in preventing rustout/burnout in estimators", Surveying and Built Environment, Vol. 18 No. 1, pp. 17-26.

Leung, M., Zhang, H. and Skitmore, M. (2008), "Effects of organizational supports on the stress of construction estimating participants", Journal of Construction Engineering and Management, Vol. 134, pp. 84-93. 
Leung, M.Y., Chan, Y.S. and Yu, J. (2009), "An integrated model for the stressors and stresses of construction project managers", Journal of Construction Engineering and Management, Vol. 135 No. 2, pp. 126-34.

Leung, M.Y., Chan, Y.S.I. and Dongyu, C. (2011), "Structural linear relationships between job stress, burnout, physiological stress, and performance of construction project managers", Engineering, Construction and Architectural Management, Vol. 18 No. 3, pp. 312-328.

Leung, M.-Y., Chan, I.Y.S. and Yu, J. (2012), "Preventing construction worker injury incidents through the management of personal stress and organizational stressors", Accident Analysis and Prevention, Vol. 48, pp. 156-166.

Lingard, H. (2003), "The impact of individual and job characteristics of 'burnout' among civil engineers in Australia and the implications for employee turnover", Construction Management and Economics, Vol. 21, pp. 69-80.

Lingard, H. and Francis, V. (2006), "Does a supportive work environment moderate the relationship between work-family conflict and burnout among construction professionals?", Construction Management and Economics, Vol. 24, pp. 185-196.

Lingard, H.C., Francis, V. and Turner, M. (2010), "The rhythms of project life: a longitudinal analysis of work hours and work-life experiences in construction", Construction Management and Economics, Vol. 28, pp. 1085-1098.

Lingard, H., Francis, V. and Turner, M. (2012), "Work time demands, work time control and supervisor support in the Australian construction industry: an analysis of work-family interaction", Engineering, Construction and Architectural Management, Vol. 19 No. 6, pp. 647-665.

Lohmöller, J.B. (1989), "Predictive vs. Structural modelling: Pls vs. ml”, Latent Variable Path Modelling with Partial Least Squares, Physica, Heidelberg.

Love, P., Smith, J., Treloar, G. and Li, H. (2000), "Some empirical observations of service quality in construction", Engineering, Construction and Architectural Management, Vol. 7 No. 2, pp. 191-201.

Luo, L., He, Q., Xie, J., Yang, D. and Wu, G. (2017), "Investigating the relationship between project complexity and success in complex construction projects", Journal of Management in Engineering, Vol. 33, p. 04016036.

Mandujano, M.G., Mourgues, C., Alarcón, L.F. and Kunz, J. (2017), "Modelling virtual design and construction implementation strategies considering lean management impacts", ComputerAided Civil and Infrastructure Engineering, Vol. 32 No. 11, pp. 930-951.

Maslach, C. (1993), "Burnout: a multidimensional perspective", in Schaufeli, W.B., Maslach, C. and Marek, T. (Eds), Professional Burnout: Recent Developments in Theory and Research, Taylor \& Francis, Washington, DC, pp. 19-32.

Maslach, C. and Leiter, M.P. (2008), "Early predictors of job burnout and engagement", Journal of Applied Psychology, Vol. 93 No. 3, pp. 498-512.

Maslach, C., Jackson, S.E. and Leiter, M.P. (1996), Maslach Burnout Inventory Manual, Consulting Psychologists Press, Calif.

Maslach, C., Schaufeli, W.B. and Leiter, M.P. (2001), "Job burnout”, Annual Review of Psychology, Vol. 52, pp. 397-422.

Meliá, J.L. and Becerril, M. (2007), "Psychosocial sources of stress and burnout in the construction sector: a structural equation model", Psicothema, Vol. 19 No. 4, pp. 679-686.

Meyers, L.S., Gamst, G. and Guarino, A.J. (2006), Applied Multivariate Research: Design and Interpretation, Sage, Thousand Oaks, CA.

Molennar, K., Washington, S. and Diekmann, J.E. (2000), "Structural equation model of construction contract dispute potential", Journal of Construction Engineering and Management, Vol. 126 No. 4, pp. 268-277.

Moore, J.E. (2000), "One road to turnover: an examination of work exhaustion in technology professionals”, MIS Quarterly, Vol. 24 No. 1, pp. 141-168. 
Murdoch, J. and Hughes, W. (2008), Construction Contracts: Law and Management, 4th ed., Taylor \& Francis, New York, NY.

Naoum, S.G., Herrero, C., Egbu, C. and Fong, D. (2018), "Integrated model for the stressors, stress, stress-coping behaviour of construction: project managers in the UK", International Journal of Managing Projects in Business, Vol. 11 No. 3, pp. 761-782.

Ng, S., Skitmore, R. and Leung, T. (2005), "Manageability of stress among construction project participants", Engineering, Construction and Architectural Management, Vol. 12 No. 3, pp. 264-282.

Nunnally, J.C. and Bernstein, I.H. (2007), Psychometric Theory, McGraw-Hill, New York, NY.

Öcal, E., Oral, E.L. and Erdis, E. (2006), "Crisis management in Turkish construction industry", Building and Environment, Vol. 41 No. 11, pp. 1498-1503.

Pallant, J. (2005), SPSS Survival Manual, Open University Press, Berkshire.

Patanakul, P., Pinto, J.K. and Pinto, M.B. (2016), "Motivation to perform in a multiple-project environment: the impact of autonomy, support, goal clarity, and opportunities for learning", Journal of Engineering and Technology Management, Vol. 39, pp. 65-80.

Pawson, R., Greenhalgh, T., Harvey, G. and Walshe, K. (2005), "Realist review-a new method of systematic review designed for complex policy interventions", Journal of Health Services Research and Policy, Vol. 10 No. 1, pp. 21-34.

Peiro, J.M., Gonzalez-Roma, V. and TorderaandManas, M.M.A. (2001), "Does role stress predict burnout over time among health care professionals?", Psychology and Health, Vol. 16, pp. 511-25.

Pinto, J.K., Dawood, S. and Pinto, M.B. (2014), "Project management and burnout: implications of the Demand-Control-Support model on project-based work", International Journal of Project Management, Vol. 32 No. 4, pp. 578-589.

Pinto, J.K., Patanakul, P. and Pinto, M.B. (2016), "Project personnel, job demands, and workplace burnout: the differential effects of job title and project type", IEEE Transactions on Engineering Management, Vol. 63 No. 1, pp. 91-100.

Poon, S.W., Rowlinson, S.M., Koh, T. and Deng, Y. (2013), "Job burnout and safety performance in the Hong Kong construction industry", International Journal of Construction Management, Vol. 13 No. 1 , pp. $69-78$.

Schaufeli, W.B. and Bakker, A.B. (2004), "Job demands, job resources, and their relationship with burnout and engagement: a multi-sample study", Journal of Organizational Behavior. The International Journal of Industrial, Occupational and Organizational Psychology and Behavior, Vol. 25 No. 3, pp. 293-315.

Schaufeli, W.B. (2017), "Burnout: a short socio-cultural history", in Neckel, S., Schaffner, A.K., Wagner, G. and Burnout (Eds), Fatigue, Exhaustion an Interdisciplinary Perspectives on a Modern Affliction, Palgrave Macmillan, London, pp. 105-128.

Stamm, B.H. (2005), The Professional Quality of Life Scale: Compassion Satisfaction, Burnout, and Compassion Fatigue- Secondary Trauma Scales, Sidran Press, Latherville, MD.

Sun, M., Zhu, F. and Sun, X. (2020), "Influencing factors of construction professionals' burnout in China: a sequential mixed-method approach", Engineering, Construction and Architectural Management, Vol. 27 No 10, pp. 3215-3233.

Tabachnick, B.G. and Fidell, L.S. (2001), Using Multivariate Statistics, Collins College Publishers, Harper New York, NY.

Tavakol, M. and Dennick, R. (2011), "Making sense of Cronbach's alpha”, International Journal of Medical Education, Vol. 2, pp. 53-55.

Toppinen-Tanner, S., Ojajärvi, A., Väänänen, A., Kalimo, R. and Jäppinen, P. (2005), "Burnout as a predictor of medically certified sickleave absences and their diagnosed causes", Journal of Behavioral Medicine, Vol. 31 No. 1, pp. 18-27.

Turk, A.M. (2006), "ISO 9000 in construction: an examination of its application in Turkey", Building and Environment, Vol. 41 No. 4, pp. 501-511. 
Wahab, A.B. (2010), "Stress management among artisans in construction industry in Nigeria", Global Journal of Researches in Engineering, Vol. 10 No. 1, pp. 93-103.

Weijing, C. and Hongchun, Y. (2011), "Analysis of the predictive indicators of knowledge workers job burnout: a perspective of organization”, paper presented to the Management Science and Industrial Engineering (MSIE), 2011 International Conference, Institute of Electrical and Electronics Engineers, Harbin, January, pp. 8-11.

Wright, T.A. and Bonett, D.G. (1997), "The contribution of burnout to work performance", Journal of Organizational Behavior, Vol. 18 No. 5, pp. 491-9.

Wu, G., Duan, K., Zuo, J., Yang, J. and Wen, S. (2016), "System dynamics model and simulation of employee work-family conflict in the construction industry", International Journal of Environmental Research and Public Health, Vol. 13, p. 1059.

Wu, G., Wu, Y., Li, H. and Dan, C. (2018), "Job burnout, work-family conflict and project performance for construction professionals: the moderating role of organizational support", International Journal of Environmental Research and Public Health, Vol. 15 No. 12, p. 2869.

$\mathrm{Wu}, \mathrm{G}$., Hu, Z. and Zheng, J. (2019), "Role stress, job burnout, and job performance in construction project managers: the moderating role of career calling", International Journal of Environmental Research and Public Health, Vol. 16, p. 239413.

Yang, F., Li, X., Zhu, Y., Li, Y. and Wu, C. (2017), "Job burnout of construction project managers in China: a cross-sectional analysis", International Journal of Project Management, Vol. 35 No. 7 , pp. 1272-1287.

Yang, F., Li, X., Song, Z., Li, Y. and Zhu, Y. (2018), "Job burnout of construction project managers: considering the role of organizational justice", Journal of Construction Engineering and Management, Vol. 144 No. 11, p. 04018103.

Yip, B. and Rowlinson, S. (2009), "Job burnout among construction engineers working within consulting and contracting organizations", Journal of Management in Engineering, Vol. 25 No. 3, pp. 122-130.

Yip, B., Rowlinson, S., Kvan, T. and Lingard, H. (2005), "Job burnout within the Hong Kong construction industry: a cultural perspective", Paper Presented at the CIB W92/T23/W107 International Symposium on Procurement Systems, pp. 8-10.

Yip, B., Rowlinson, S. and Siu, O.L. (2008), "Coping strategies as moderators in the relationship between role overload and burnout", Construction Management and Economics, Vol. 26 No. 8, pp. 871-882.

Zhang, L., Yao, Y. and Yiu, T.W. (2020), "Job burnout of construction project managers: exploring the consequences of regulating emotions in workplace", Journal of Construction Engineering and Management, Vol. 146 No. 10, p. 04020117.

Zhao, Z.Y. and Chen, Y.L. (2018), "Critical factors affecting the development of renewable energy power generation: evidence from China”, Journal of Cleaner Production, Vol. 184, pp. 466-480.

Zheng, H., Shao, H. and Zhou, Y. (2018), "Burnout among Chinese adult reconstructive surgeons: incidence, risk factors, and relationship with intraoperative irritability", The Journal of Arthroplasty, Vol. 33 No. 4, pp. 1253-1257.

\section{Corresponding author}

Gulden Gumusburun Ayalp can be contacted at: gulden.ayalp@hku.edu.tr

\section{Critical predictors of burnout}

